\title{
Adsorption of Phenol and Chlorophenol Mixtures on Silicalite-1 Determined by GC-MS Method
}

Zareth Ortiz-Arzate, ${ }^{1,4}$ Thelma S Jiménez-Bravo, ${ }^{1}$ Norma A. Sánchez-Flores, ${ }^{2}$ Graciela Pacheco-Malagón, ${ }^{2}$ Silvia Bulbulian, ${ }^{2}$ and Ignacio A. Rivero ${ }^{1,3} *$

${ }^{1}$ Instituto Nacional de Investigaciones Nucleares, Departamento de Química, México D.F., México.

${ }^{2}$ Centro de Ciencias Aplicadas y Desarrollo Tecnológico, Universidad Nacional Autónoma de México, Av. Universidad 3000 Col. Universidad Nacional Autónoma de México, Ciudad Universitaria. AP. 70-186, Delegación Coyoacán, C.P. 04510, México D. F. México.

${ }^{3}$ Centro de Graduados e Investigación en Química del Instituto Tecnológico de Tijuana. Apartado Postal 1166, Tijuana, B. C. 22000 México.irivero@tectijuana.mx

${ }^{4}$ Universidad Autónoma del Estado de México, Toluca, México.

Received October 4, 2012; accepted April 22, 2013

\begin{abstract}
A method is presented in which gas chromatography coupled with mass spectrometry (GC-MS) allows quantitative simultaneous detection of mixtures of phenol $(\mathrm{Ph}), 2$-chlorophenol (2-CPh), 3 -cholorphenol (3-CPh), and 4-cholorophenol (4-CPh) in aqueous mixtures after being adsorbed on silicalita-1, utilizing selected-ion monitoring (SIM) and full-scan modes mass selective detection. GCMS with SIM at $m / z=64$ and $m / z=128$ showed good detection selectivity for mixtures of $\mathrm{Ph}, 2-\mathrm{CPh}$ and 3-CPh $\left(\mathrm{M}_{1}\right)$, and 2-CPh and 4-CPh $\left(\mathrm{M}_{2}\right)$. Silicalita-1 was obtained from an amorphous organo-alumino-silicic gel from rice husk, an abundant and low cost agricultural waste residue that is readily available in large quantities. This product was used as a sorbent for solid phase extraction of organic analytes from aqueous solutions. The adsorption of the three chlorophenol isomers, ortho-, meta-, and para-, by silicalite- 1 has been studied independently, showing that meta- and para-chlorophenol isomers are adsorbed more than ortho-chlorophenol. However the adsorption behavior of mixtures of these isomers was not reported. In this work, it was found that when the ortho-isomer is mixed either with metaor para-chlorophenol, considerable differences were observed in the adsorption process; in the studied mixture, the ortho-isomer was adsorbed more than the meta-and para-chlorophenol.

Key words: Silicalite-1, rice husk, GC-MS, ortho-chlorophenol, meta-chlorophenol, para-chlorophenol.
\end{abstract}

\section{Introduction}

Phenols and related compounds are toxic to humans and aquatic life. Chlorophenols are formed as metabolites of agricultural pesticides, in pulp bleaching processes, and as byproducts of the chlorination of drinking waters (NMx-AA-050-1981) [1]. The adsorption technique is one of the alternative treatment processes currently being considered to achieve required levels in the removal of phenols. The adsorption of phenols by different adsorbents has been investigated to identify the relationship between adsorption capacity and adsorbent characteristics such as surface area and pore size distribution for separation applications in the drinking water concentration range [2].

Activated carbon, as one of the active adsorbents, has been extensively used in the process due to its predominant proportion of micropores. Alternative adsorbents studied include
Resumen. En este trabajo se presenta un método cromatográfico acoplado a la espectrometría de masas (GC-MS) que permite la detección simultánea de fenol(Ph), 2-clorofenol (2-CPh), 3-clorofenol (3-CPh), y 4-clorofenol (4-CPh) en mezclas acuosas después de ser adsorbidas sobre silicalita-1, utilizando iones previamente seleccionados y el espectro completo de iones. Los iones en SIM de $m / z=64$ y 128 mostraron una buena detección y selectividad para mezclas de $\mathrm{Ph}, 2-$ $\mathrm{CPh}$, y $3 \mathrm{CPh}\left(\mathrm{M}_{1}\right)$ y 2-CPh y $4-\mathrm{Cph}\left(\mathrm{M}_{2}\right)$. La silicalita-1 se obtuvo a partir de un gel órgano-alumino-silícico amorfo proveniente de cáscara de arroz, material abundante y de bajo costo, dado que proviene de residuos agrícolas disponibles fácilmente en grandes cantidades. Este producto se utilizó como un sorbente en la extracción en fase sólida de analitos orgánicos a partir de soluciones acuosas. La adsorción de los tres isómeros de clorofenol, orto, meta, y para, por la silicalita-1 ha sido estudiada de forma independiente, mostrando que los isómeros meta y para clorofenol se adsorben más que el orto-clorofenol. Sin embargo, el comportamiento de adsorción de mezclas de estos isómeros no se ha reportado. En este trabajo, se ha encontrado que cuando el isómero orto se encuentra en mezcla con el meta o para-clorofenol presentan diferencias considerables, como se observó en el proceso de adsorción; en la mezcla estudiada el isómero orto se adsorbe más que el meta y para-clorofenol.

Palabras clave: Silicalita-1, cáscara de arroz, CG-EM, orto-clorofenol, meta-clorofenol, para-clorofenol.

naturally occurring materials such as biosorbentes [6], clays, zeolites, and resins [7].

Silicalite-1 (SLC-1), which has a similar structure to ZSM5 , is a molecular sieve that was first synthesized in early 1970 s [8]. It was obtained from rice husk through a calcinations process under specific conditions that allow retention of organic matter $[9,10]$. This material is a zeolite with a high content of silica $[11,12]$. SLC-1 is hydrophobic and can remove organic molecules in liquid or gaseous samples. It is a polymorph of silica with an unusual crystal structure. It has a tetrahedral geometry of mostly 5-membered rings of silicon-oxygen tetrahedra. This spatial distribution has interesting channels with a diameter of $6 \AA$ that are defined by rings of 10 oxygen atoms [8].

The high hydrophobicity of SLC-1 allows it to capture aromatic components of highly toxic simple structures, among 
them phenol and related compounds, that are difficult to remove, are persistent, and can alter the organoleptic properties of drinking water, causing unpleasant taste and odor. Many techniques have been studied for detection of chlorophenols (CPhs); however, gas chromatography-mass spectrometry (GCMS) has the inherent advantage of high selectivity, specificity, and sensitivity, and has become the technique of choice for $\mathrm{CPhs}$ analysis.

GC-MS is a powerful technique for quantitative and qualitative analysis and has been successfully applied in many areas, including environmental analysis [19], food-related applications, toxicological and forensic application [20], and ubiquitously in the petroleum industry [21]. GC-MS provides high-resolution separation with highly selective and sensitive detection, which is of utmost importance in qualitative analysis.

A mass spectrometer is typically used in one of two ways: full scan or selective ion monitoring (SIM) for identification or quantification purposes, respectively $[13,14,15,16]$. The advantages of SIM are that the detection limit is lower since the instrument is only looking at a small number of fragments (e.g., three fragments) during each scan. The typical GC-MS instrument can perform both functions either individually or concomitantly, depending on the setup of the particular instrument.

The adsorption capacity of phenol and chlorinated phenols by different adsorbents has been well studied [22, Mangrulkar et al. 2008; Yogesh et al. 2008], but mixtures of these isomers have not been studied. Therefore, the purpose of this work is to investigate the simultaneous adsorption of mixtures of phenol $(\mathrm{Ph})$ and $\mathrm{CPhs}$ on silicalita-1 obtained from amorphous organoalumino-silicic gel from rice husk utilizing the gas chromatography-mass spectrometry (GC-MS) method. The SLC-1 sample was derived from rice hull ashes [Sánchez-Flores et al. 2008].

\section{Experimental Methods}

\section{Materials and Methods}

Reagent-grade chemicals were used as received without further purification. $\mathrm{Ph}(100 \%)$ was obtained from Productos Monterrey S.A.; ortho-chlorophenol (2-CPh), meta-chlorophenol (3$\mathrm{CPh})$, and para-chlorophenol (4-CPh) (>98\%) were obtained from Sigma Aldrich.

\section{Adsoption process}

Pure solutions of $\mathrm{Ph}$ and $\mathrm{CPhs}$ and different mixtures of these reagents were prepared, the first one (M1) with $\mathrm{Ph}, 2-\mathrm{CPh}$, and 3- $\mathrm{CPh}$ and the second one $\left(\mathrm{M}_{2}\right)$ with $2-\mathrm{CPh}$ and $4-\mathrm{CPh}$, both in a total volume of $3 \mathrm{~mL}$ at a concentration of $1.6 \mathrm{mM} / \mathrm{L}$. All solutions in the vessels were then submerged in a water bath with a heating system that was adjusted to a constant temperature of $30^{\circ} \mathrm{C}$. A known weight of adsorbent (3 mg of SLC-1) was immersed in the vessel, and agitation was immediately initiated (speed of stirring $=120 \mathrm{rpm}$ ) for $72 \mathrm{~h}$ using a Cole
Parmer Polystat, model 12050-00. The solids were separated by centrifugation and were extracted with chloroform.

\section{GC-MS study}

Sample analysis was performed on Agilent 6890NGC coupled to Agilent 5973 Network MSD operated in the electron ionization mode. The analytical column was a HP-5MS, $30 \mathrm{~m} \times$ $0.25 \mathrm{~mm}$ fused silica column with $0.25 \mu \mathrm{m}$ ( $5 \%$ phenyl)-methylsiloxane stationary phase. The column temperature program was $45^{\circ} \mathrm{C}(4 \mathrm{~min})-\left(9^{\circ} \mathrm{C} / \mathrm{min}\left(75^{\circ} \mathrm{C}\right)\right)(5 \mathrm{~min})-\left(14^{\circ} \mathrm{C} / \mathrm{min}(220\right.$ $\left.\left.{ }^{\circ} \mathrm{C}\right)\right)(4 \mathrm{~min})$, using helium as a carrier gas. A $1 \mu \mathrm{L}$ sample was injected into the GC using a splitless mode on-column injector employed to obtain maximum sensitivity. Standard ionization energy of $70 \mathrm{eV}$ was used.

Full scans were acquired under the following condition: mass range $=45-135 \mathrm{amu}$, scan data $=5.98 \mathrm{cycles} / \mathrm{s}$. SIM mode studies were obtained by monitoring single ion at $m / z=64$ and $m / z=128$. Total ion chromatogram of mixture of $2-\mathrm{CPh}$ and 3-CPh were also presented.

The mass spectra were compared with the NIST library. Qualitative analysis was done by total ion chromatogram (TIC) and/or fragment ions with SIM selected.

The amount of chlorophenols retained by SLC-1 was calculated by determining the difference of the concentration in the original standard $(1.6 \mathrm{mM} / \mathrm{L})$ and in the equilibrium solutions. The amount of $\mathrm{CPhs}$ retained was obtained using the following equation:

$$
Q_{a}=\left[\left(\frac{C_{o}-C_{e}}{g_{\text {silicalitel }}}\right)\right] \cdot V
$$

where $Q a$ is the adsorption capacity of $\mathrm{Ph}$ and/or CPhs on silicalite-1(mg /g SLC-1), $V$ is the volume of the solution utilized $(L)$, and $\mathrm{g}$ is the weight of each sample.

\section{Characterization}

\section{Surface area and pore size distribution}

$\mathrm{N}_{2}$ adsorption/desorption isotherms and specific surface area were measured with a BELSORP-MAX equipment after outgassing overnight at $300{ }^{\circ} \mathrm{C}$. The specific surface area was calculated by the Langmuir method and the pore size distribution was calculated using the MP method.

\section{Scanning electron microscopy}

For scanning electron microscopy (SEM) observations, the SLC-1 samples before and after the adsorption process were supported on carbon and coated with a thin layer of gold. Then samples were analyzed at $20 \mathrm{kV}$ in a JEOL JSM-5900LV electron microscope. The microanalysis was performed with an EDS (energy X-ray dispersive spectroscopy) system. 


\section{X-Ray diffraction (XRD)}

Powder diffractograms of the SLC-1 samples were obtained with a SIEMENS D5000 diffractometer coupled to a copper anode X-ray tube. The diffractograms were used to identify the compounds and to verify crystalline structure. They were compared with a silicalita-1-standard (JCPDS 73-6453).

\section{FT-IR spectroscopy and Raman spectroscopy}

Fourier transformed-infrared spectra (FT-IR) and Raman spectra were collected respectively from a Nicolet model 550 and a Jobin Yvon Labram HR with a $532 \mathrm{~nm}$ laser wavelength. For infrared spectra, the samples were prepared with the standard $\mathrm{KBr}$ pellet.

\section{Thermogravimetric analyses (TGA)}

Thermogravimetric analyses were carried out with a SDT model Q600 instrument under nitrogen gas flow and a constant heating rate of $10^{\circ} \mathrm{C} / \mathrm{min}$.

\section{Results and Discussion}

\section{Gas chromatography-mass spectrometry (GC-MS)}

Typical total ion chromatogram (TIC) for $\mathrm{Ph}, 2-\mathrm{CPh}, 3-\mathrm{CPh}$, and $4-\mathrm{CPh}$ are shown in Figure 1. $\mathrm{Ph}$ and 2-CPh have similar retention times $(\approx 9.5 \mathrm{~min})$, whereas $3-\mathrm{CPh}$ and $4-\mathrm{CPh}$ have a retention time of $\approx 16.5 \mathrm{~min}$. Thus, it is not possible to study the adsorption behavior of a mixture of 3-CPh and 4-CPh on SLC-1 by this method; however, we found that the gas chromatography-mass spectrometry (GC-MS) method is valid for two different mixtures of $\mathrm{Ph}$ and $\mathrm{CPh}$ isomers: $\mathrm{M}_{1}(\mathrm{Ph}, 2-\mathrm{CPh}$, and 3-CPh) and $\mathrm{M}_{2}$ (2-CPh and 4-CPh) (Figs. 2 and 3). Two characteristic fragment ions with the highest abundance $(\mathrm{m} / \mathrm{z}$ $=64,128)$ were selected for additive SIM detection. The postulated structures of those fragments are illustrated in Figures $3 \mathrm{~b}$ and $3 \mathrm{c}$.

In preliminary experiments, the adsorption capacity of each of the $\mathrm{Ph}$ and $\mathrm{CPh}$ isomers by silicalite- 1 was studied. It was shown that under the working conditions and using an initial concentration of $1.6 \mathrm{mMol} / \mathrm{L}$, the adsorption relation (Ra) of ortho-clorophenol (0.82) is lower than the meta- (1.00) and para-chlorophenol (0.99) isomers in water by silicalita-1.

SIM mode and splitless injection were used to maximize selectivity and sensitivity. A summary of the results obtained from GC-MS are presented in Tables 1 and 2, which show retention time (RT), final concentration in solution (Cf), amount adsorbed $(\mathrm{Qa})$, and adsorption relation $(\mathrm{Ra})$.

The obtained results for the individual adsorption of the chlorophenol isomers and those obtained for the mixtures of these compounds (Tables 1 y 2) show that the adsorption capacity of ortho-chlorophenol is lower than the adsorption capacities of meta-and para-chlorophenol isomers in water by silicalita-1 when the isomers are not mixed. When the isomers are mixed, however, the results are very different. The relative
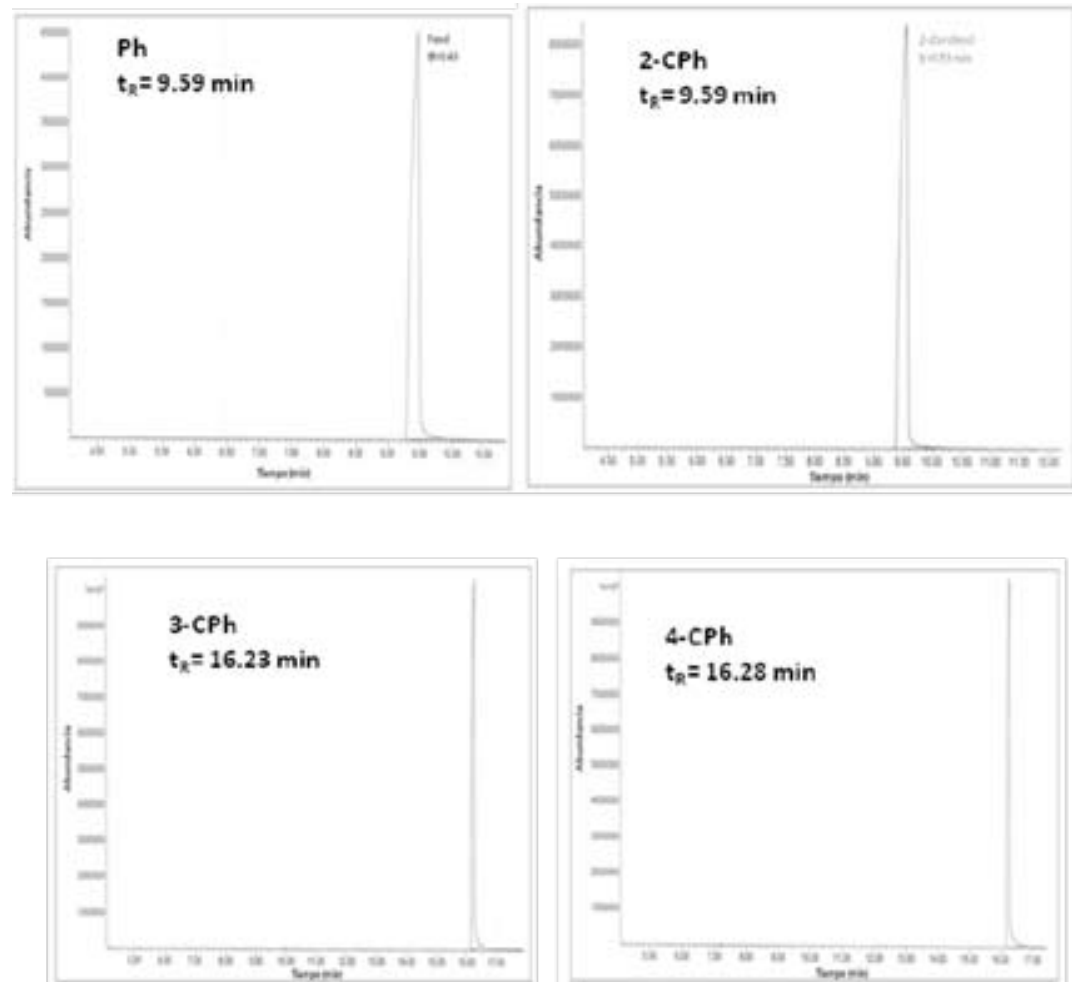

Figure 1. Total ion chromatogram of phenol and chlorophenols in study. 

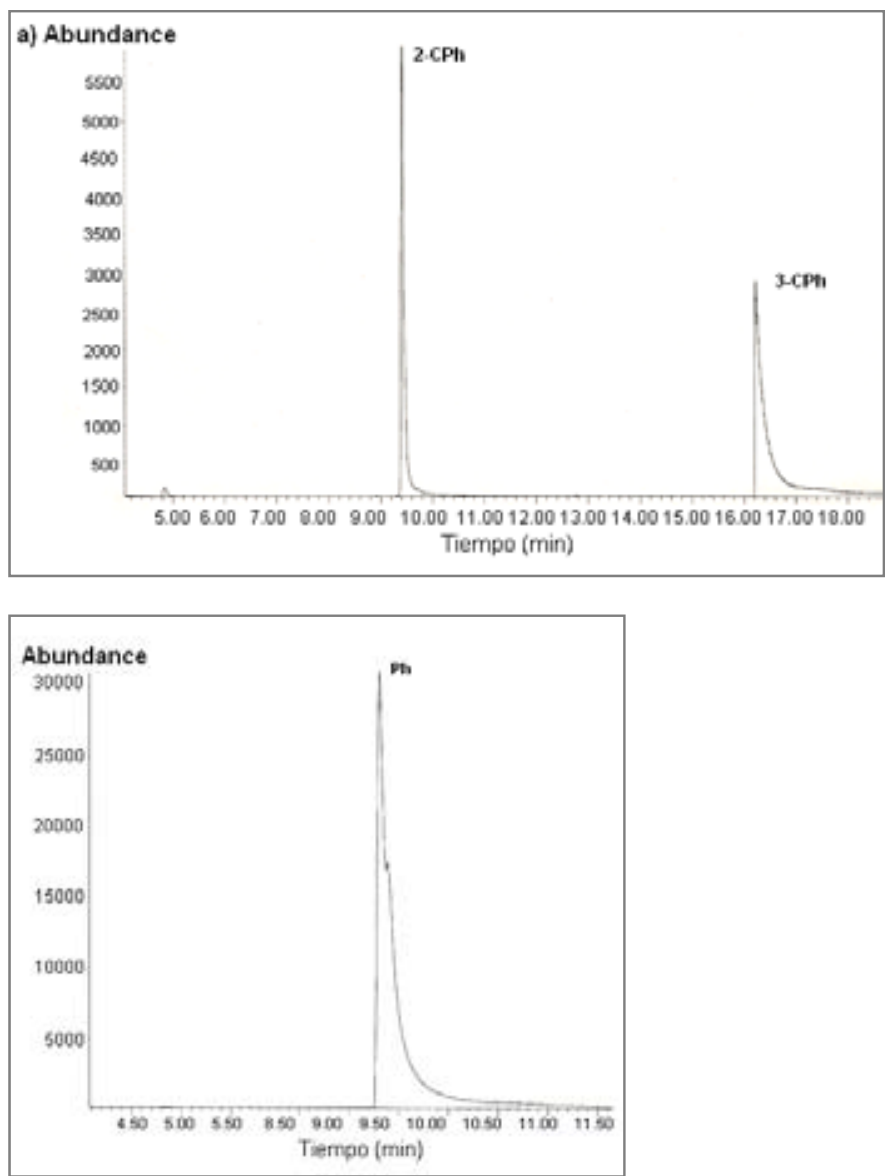

Figure 2. Total ion chromatogram of $\mathrm{Ph}, 2-\mathrm{CPh}$, and 3-CPh.

Table 1. Adsorption capacity $\mathrm{Q}_{\mathrm{a}}$ of $\mathrm{Ph}$ and $\mathrm{CPhs}$ in $\mathrm{M}_{1}$ on silicalita1 .

\begin{tabular}{ccccc}
\hline CLP & $\begin{array}{c}\mathrm{RT} \\
(\mathrm{min})\end{array}$ & $\begin{array}{c}\mathrm{C}_{\mathrm{f}} \\
(\mathrm{mmol} / \mathrm{L})\end{array}$ & $\begin{array}{c}\mathrm{Q}_{\mathrm{a}} \\
(\mathrm{mgCLP} / \mathrm{gSLC}-1)\end{array}$ & $\mathrm{R}_{\mathrm{a}}$ \\
\hline $\mathrm{Ph}$ & 9.379 & 1.357 & 22.86 & 0.36 \\
$2-\mathrm{CPh}$ & 9.449 & 1.110 & 62.99 & 1.00 \\
$3-\mathrm{CPh}$ & 16.285 & 1.329 & 34.84 & 0.55 \\
\hline
\end{tabular}

Conditions: MSD SIM, $\mathrm{Q}_{\mathrm{SLC}-1}=3 \mathrm{mg}, \mathrm{C}_{\mathrm{i}}=1.6 \mathrm{mMol} / \mathrm{L}, \mathrm{V}=3 \mathrm{E}-3 \mathrm{~mL}$, $\mathrm{W}_{\mathrm{F}}=94.11 \mathrm{~g} \mathrm{~W}_{2-\mathrm{CF}-3 \mathrm{CF}}=128.56 \mathrm{~g}$

adsorption of the ortho isomer increases highly compared to the adsorption of the other two isomers when they are mixed either in sample $\mathrm{M}_{1}$ or sample $\mathrm{M}_{2}$.

\section{Textural properties}

Figure 4 shows the shape of the isotherm corresponding to the microporosity per se of the silicalite-1 and the mesoporosity contribution due to the non crystalline silica. The specific surface area and pore total volume of the SLC-1 sample were studied. The surface area was found to be $499.3 \mathrm{~m}^{2} / \mathrm{g}$. Surface contained two types of pores, micro and mesoporous. This behavior is attributed to the fact that silicalita- 1 is derived from rice hull
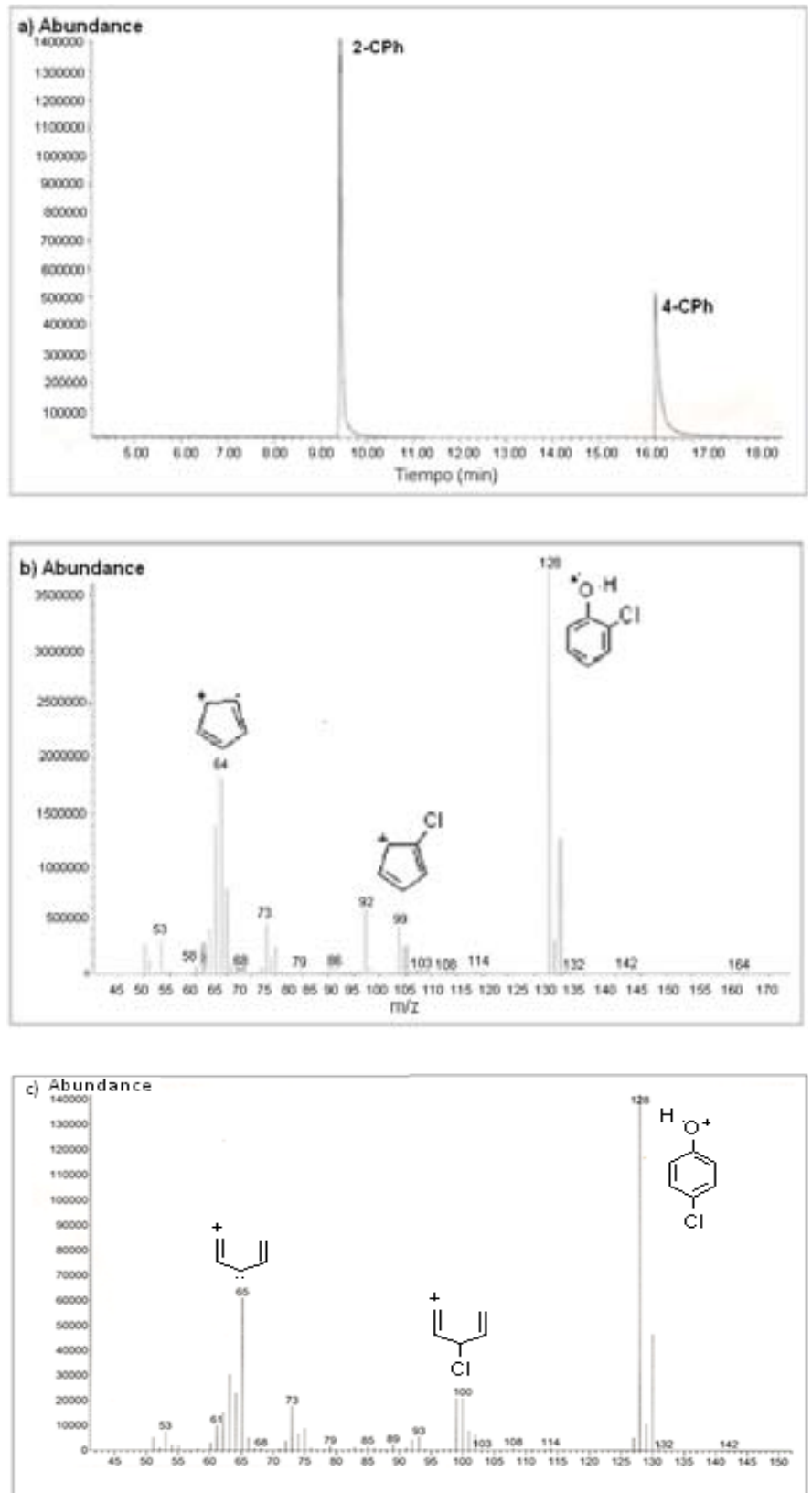

Figure 3. (a) Total ion chromatogram of 2-CPh and 4-CPh. Mass spectrum by EI of 2-CPh (b) and 4-CPh (c).

Table 2. Adsorption capacity $\mathrm{Q}_{\mathrm{a}}$ of $\mathrm{Ph}$ and $\mathrm{CPhs}$ in $\mathrm{M}_{2}$ on silicalita1.

\begin{tabular}{ccccc} 
CLP & $\begin{array}{c}\mathrm{RT} \\
(\mathrm{min})\end{array}$ & $\begin{array}{c}\mathrm{C}_{\mathrm{f}} \\
(\mathrm{mmol} / \mathrm{L})\end{array}$ & $\begin{array}{c}\mathrm{Q}_{\mathrm{a}} \\
(\mathrm{mgCLP} / \mathrm{gSLC}-1)\end{array}$ & $\mathrm{R}_{\mathrm{a}}$ \\
\hline 2-CPh & 9.440 & 1.191 & 52.58 & 1.00 \\
$3-\mathrm{CPh}$ & 16.219 & 1.301 & 38.44 & 0.73 \\
\hline
\end{tabular}

ashes. The microporous region was analyzed by MP method, showing two diameters, 0.6 and $0.9 \mathrm{~nm}$ and a $t$-plot micropore volume of $0.0968 \mathrm{cc} / \mathrm{g}$. By adjusting to a bimodal distribution, it is found that $0.6 \mathrm{~nm}$ is the most frequent diameter. 


\section{Scanning electron microscopy}

The shape of the grains of the SLC-1 material after adsorption of the $\mathrm{M}_{1}$ and $\mathrm{M}_{2}$ samples determined by SEM (Figure 5) are not different from the original ones, but the sizes of the crystals are much smaller and irregular. The original SLC-1 samples have large crystals of about $4.88 \mu \mathrm{m}$ and wide $1.67 \mu \mathrm{m}$; their thickness seems to be about $500 \mathrm{~nm}$. The particle's surface is smooth and typical of a well crystallized material (see Figure
$4 a)$. On the other hand, after adsorption of $\mathrm{M}_{1}$ or $\mathrm{M}_{2}$ solutions, the sizes of the crystals change at about $2.8 \mu \mathrm{m} \times 1.33 \mu \mathrm{m} \times$ $500 \mathrm{~nm}$ for $\mathrm{M}_{1}$ and $8.81 \mu \mathrm{m} \times 1.39 \mu \mathrm{m} \times 500 \mathrm{~nm}$ for $\mathrm{M}_{2}$, but the crystalline structure is preserved.

The elemental composition analysis of SLC-1 is shown in Table 3. The main elements are $\mathrm{Si}$ and $\mathrm{O}$. O/Si ratio is 1.71 for original SLC-1 and 2.07 and 1.95 for SLC- 1 after the adsorption of M1 and M2, respectively. The increase in the ratio is due to the presence of the hydroxyl groups from $\mathrm{CPh}$ interaction.

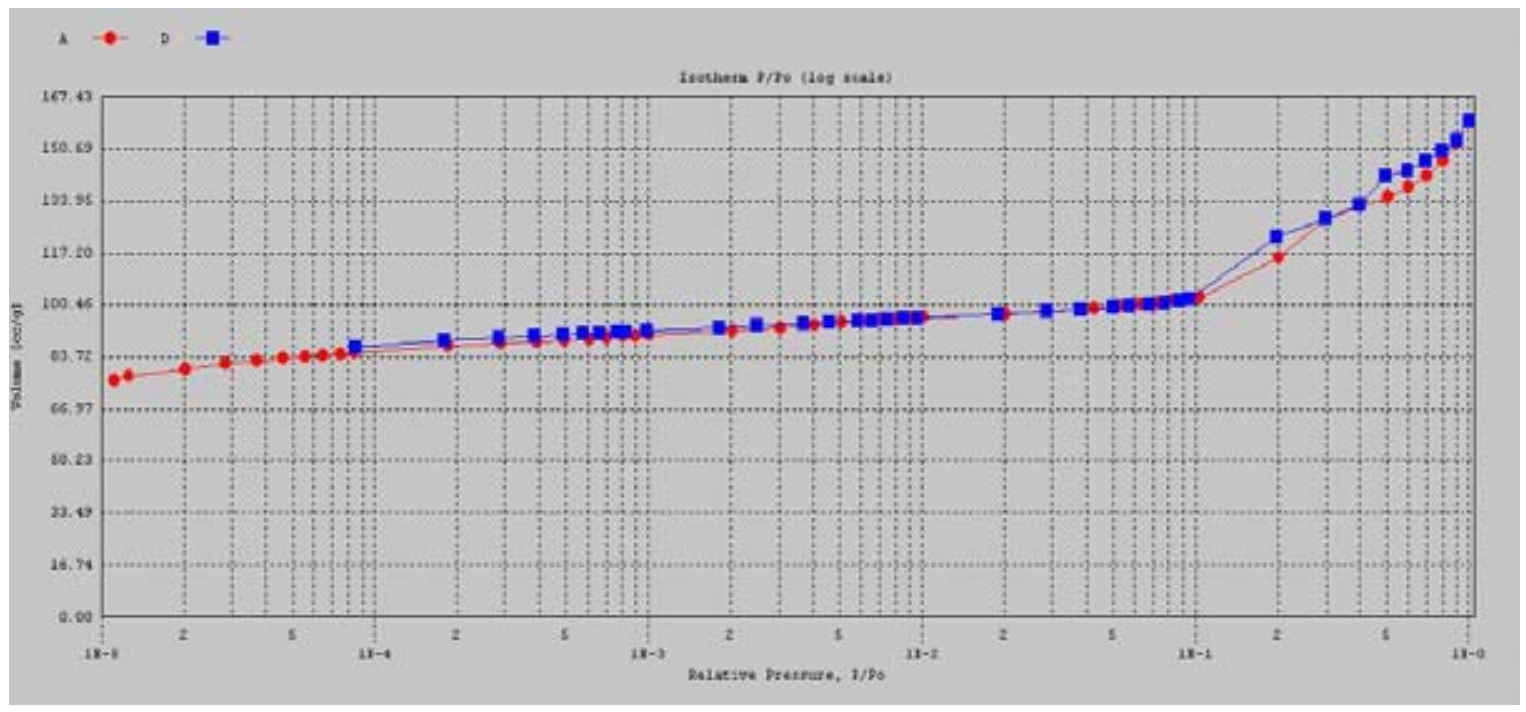

Figure 4. $\mathrm{N}_{2}$ physical adsorption and desorption isotherm.

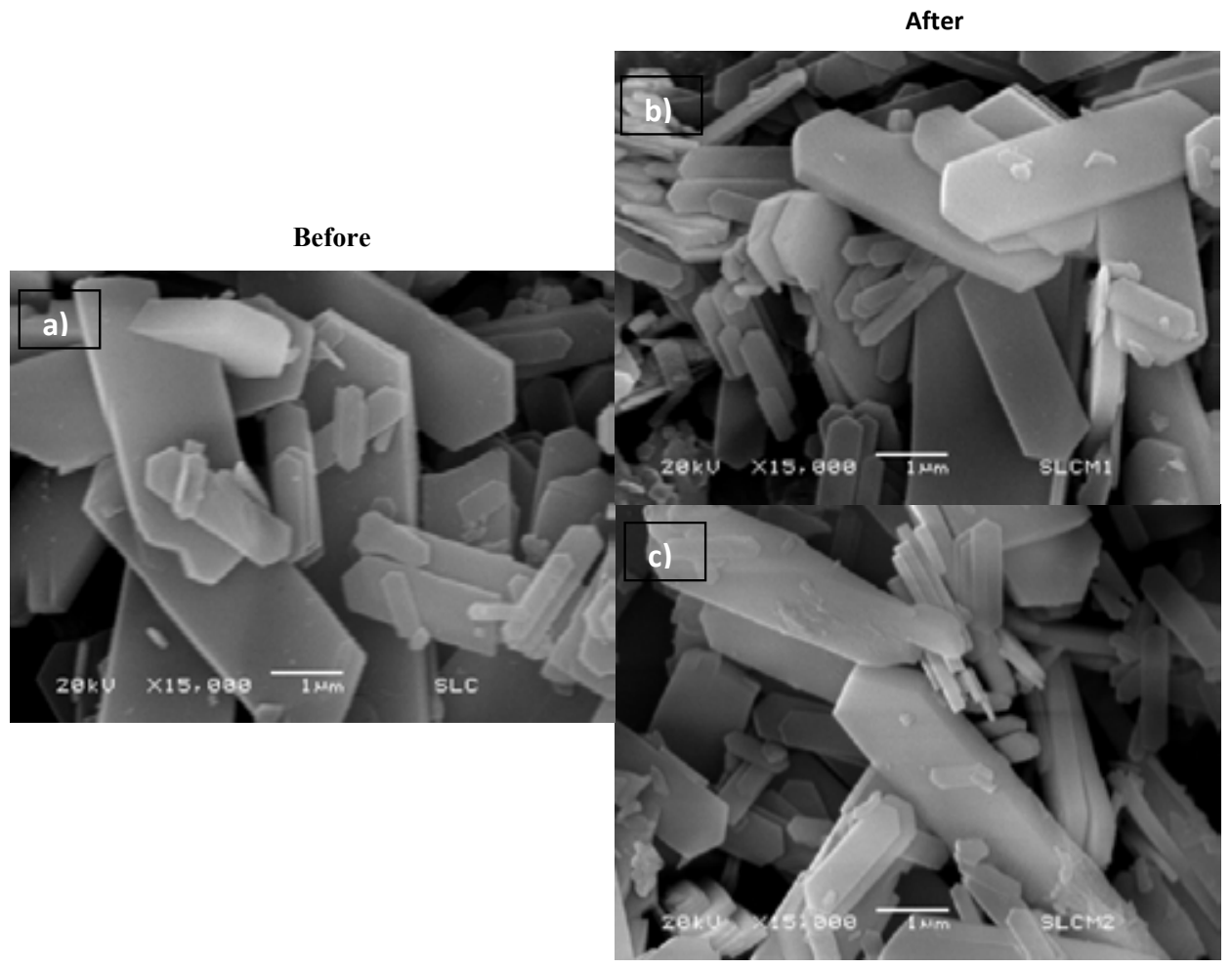

Figure 5. Scanning electron micrographs of (a) SLC-1 sample, (b) SLC-1+M 1 , and (c) SLC-1+M . 
Table 3. EDS analysis of the SLC-1 before and after the adsorption process.

\begin{tabular}{cccc}
\hline Element & SLC $\%$ & $\mathrm{SLC} \mathrm{M}_{1} \%$ & $\mathrm{SLC}+\mathrm{M}_{2} \%$ \\
\hline $\mathrm{C}$ & 17.79 & 31.91 & 29.78 \\
$\mathrm{O}$ & 51.61 & 45.67 & 46.06 \\
$\mathrm{Mg}$ & 0.11 & 0.08 & 0.09 \\
$\mathrm{Si}$ & 30.12 & 22.00 & 23.65 \\
$\mathrm{~K}$ & 0.12 & - & - \\
$\mathrm{Cl}$ & - & 0.26 & 0.35 \\
$\mathrm{Ca}$ & 0.26 & 0.08 & 0.08 \\
\hline
\end{tabular}

\section{X-Ray diffraction (XRD)}

The X-ray powder diffraction patterns of SLC-1 (Figure 6) samples before and after the adsorption process were similar. The diffractograms were compared with a silicalita-1 standard pattern (JCPDS 73-6453), showing a good correspondence. No other compounds were observed.

\section{FT-IR spectroscopy and Raman spectroscopy}

Figure 7 shows the FT-IR transmission spectra of the SLC-1 original sample and of those obtained after adsorption of $\mathrm{M}_{1}$ or $\mathrm{M}_{2}$ samples. The bands due to $\mathrm{SiO}_{4}$ tetrahedra are shown in Figure 7a. The first two are clearly resolved at 1232 and 1101 $\mathrm{cm}^{1}$ (asymmetric stretching) and the other three bands at 793, 546 , and $490 \mathrm{~cm}^{1}$ (symmetric stretching) are conserved after the adsorption. The bands $\mathrm{C}=\mathrm{C}, \mathrm{O}-\mathrm{H}$, and $\mathrm{C}-\mathrm{Cl}$ groups are found at $1600,3640-3610,800$, and $600 \mathrm{~cm}^{-1}$, respectively (see Figures $7 \mathrm{~b}$ and $7 \mathrm{c})[3,4,5]$.

Raman spectra of the aluminosilicate show a band at 385 $\mathrm{cm}^{-1}$, characteristic of the five member building units of the zeolite (Figure 8). This vibration is similar to those presented by zeolite ZSM-5 [6, 17]. Phenol and chlorine compounds are immersed in the support after the adsorption process, present-

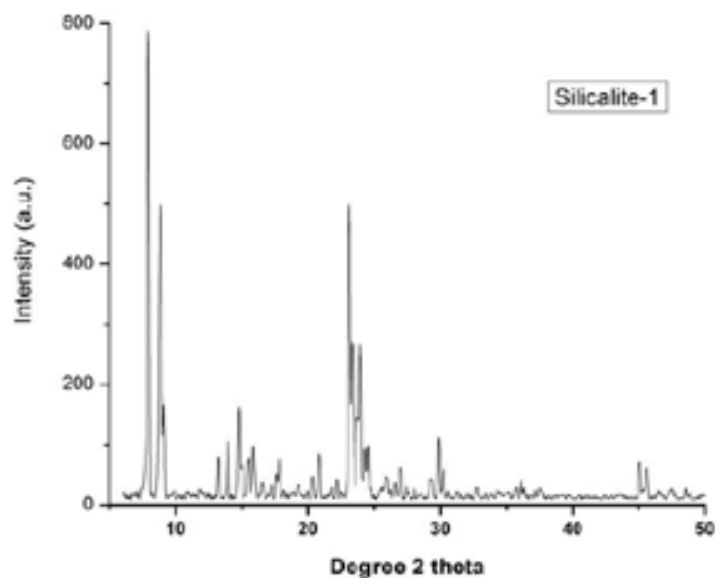

Figure 6. X-ray diffraction pattern of silicalite-1 from rice hull ashes.

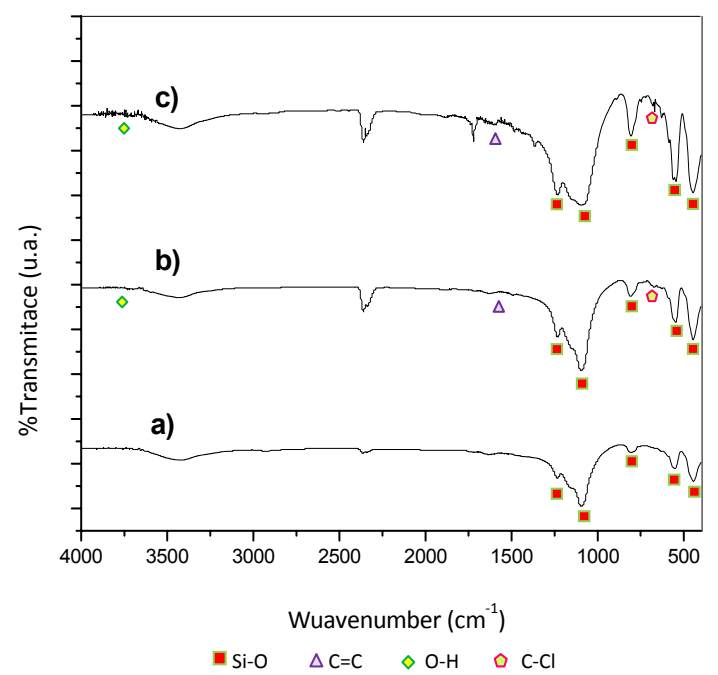

Figure 7. FT-IR spectra of SLC-1 samples: a) SLC-1 before adsorption process; b) SLC-1 after adsorption of $\mathrm{M}_{1}$; c) SLC-1 after adsorption of $\mathrm{M}_{2}$.

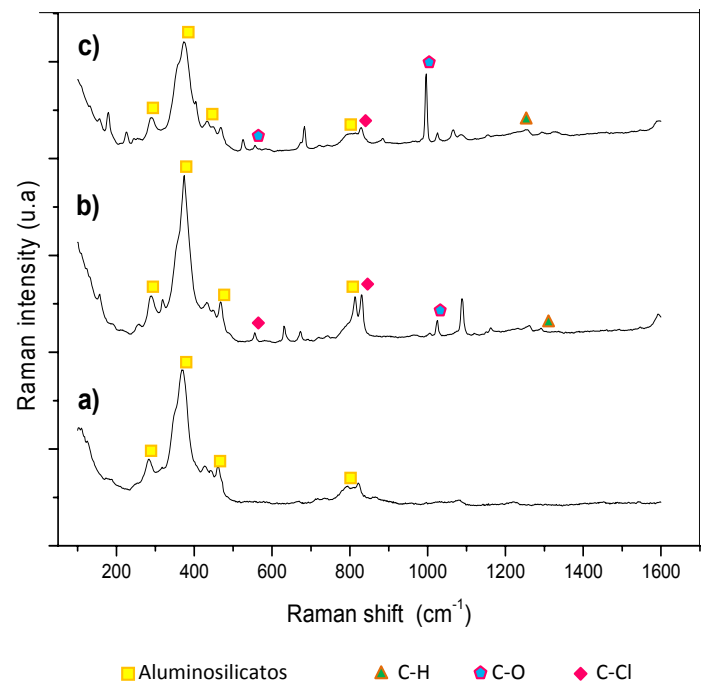

Figure 8. Raman spectra SLC-1 samples: a) SLC-1 before adsorption process; b) SLC-1 after-adsorption of $\mathrm{M}_{1}$; c) SLC-1 after adsorption of $\mathrm{M}_{2}$.

ing stretching vibrations of phenol in 1007 and $507 \mathrm{~cm}^{1}$ [18] and chlorinated compounds appreciated in bands 824-823, 810, and $528-556 \mathrm{~cm}^{1}$.

\section{Thermogravimetric analyses (TGA)}

The weight losses of the SLC-1 original sample and of those after adsorption of $\mathrm{M}_{1}$ or $\mathrm{M}_{2}$ solutions are compared in Figure 9. Up to $200{ }^{\circ} \mathrm{C}$ adsorbed water is lost. From 200 to $600^{\circ} \mathrm{C}$, decomposition of interlayered species occurs. All profiles are similar, showing that $\mathrm{M}_{1}$ and $\mathrm{M}_{2}$ adsorption does not alter the thermal behavior. The total weight loss for the original sample is $2.5 \%$, and for those that have adsorbed $\mathrm{M}_{1}$ and $\mathrm{M}_{2} \mathrm{CPhs}$ mixtures, weight loss is $5.6 \%$ and $5.5 \%$, respectively. 


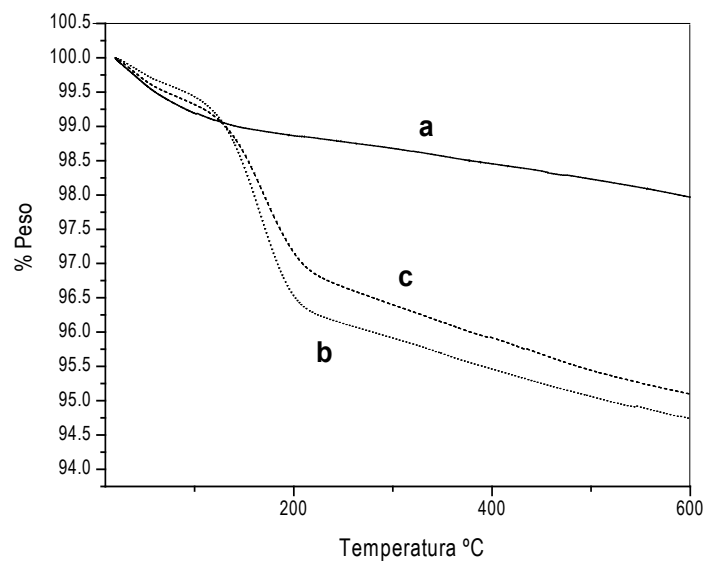

Figure 9. Thermograms of SLC-1 samples. a) SLC-1 before adsorption process, b) SLC-1 after adsorption of $\mathrm{M}_{1}$; c) SLC-1 after adsorption of $\mathrm{M}_{2}$.

\section{Conclusions}

SLC-1 has an intricate system. Its channels are able to retain different phenolic compounds, but different $\mathrm{CPh}$ isomers have different adsorption capacities on this adsorbent. Using GC$\mathrm{MS}$ as a system for detection of $\mathrm{Ph}, 2-\mathrm{CPh}, 3-\mathrm{CPh}$, and 4-CPh present in water, we developed a simple procedure allowing the simultaneous analysis of this group of compounds when they are mixed. This method allows accurate identification and quantification of phenolic compounds with high sensitivity.

\section{Acknowledgements}

We thank the Instituto de Ciencia y Tecnología del Distrito Federal de México for financial support (ICyTDF 034/2009) and the surface area work of I.Q. Viridiana Maturano (CCADET) is gratefully recognized.

\section{References}

1. Geibler, A.; Schöler. H.F. Wat. Res. 1994, 28, 2047-2053.

2. Roostaei, N.; Tezel. H. J. Environ. Manag. 2004, 70, 157164.

3. Morrison, R.T.; Boyd, R.N. (1998). Química orgánica. $6^{a}$ ed., Pearson Education, México.

4. Rubinson, F. y Rubinson, J. (2000). Analítica contemporánea. 1a ed., Prentice Hill, México.

5. Sierra L.; Henao S. (2004). Diseño de una Planta Piloto para la Obtención del Colorante de la Cáscara de Plátano Hartón. Resumen de los trabajos de grado. Universidad EAFIT. Medellín.

6. Aksu, Z. Process Biochemistry 2005, 40, 997-1026.

7. Ahmaruzzaman, Md. A review. Advances in colloidal and interface science 2008, 143, 48-67.

8. Mayer, D.L.; Fritz. J.S. J. Chromatogr. 1997, 771, 45-53.

9. Richard, D.; Delgado, M.L.; Schweich. D. Chem. Eng. J. 2009, 148, 1-7.

10. Sánchez, N.A.; Pacheco, G.; Pérez, P.; Armendariz, H.; Guzmán, M.L.; Saniger, J.M.; Fripiat. J.J. J. Chem. Technol. Biotechnol. 2007, 82, 614-619.

11. Kalapathy, U.; Proctor, A.; Shultz. J. J. Chem. Technol. Biotechnol. 2000, 75, 464-468.

12. Hamdan, H.; Mohd, M.N.; Endud, S.; Listiorini, E.; Ramli, Z. J. Non-Cryst. Sol. 1997, 211, 126-131.

13. Hao, C.; Zhao, X.; Yang. P. Trends in Analytical Chemistry 2007, 6, 569-580.

14. Zhang, Z.L.; Hibberd, A.; Zhou. J.L. Anal. Chim. Acta 2006, 577, 52-61.

15. Koutsouba, V.; Heberer, T.; Fuhrmann, B.; Schmidt-Baumler. K.; Tsipi. D.; Hiskia, A. Chemosphere 2003, 51, 69-75.

16. Zühlke, S.; Dünnbier, U.; Heberer. T. J. Chromatogr. A 2004, 1050, 201-209

17. Dutta, P.K.; Puri. M. J. Phys. Chem. 1987, 91, 4329-4333.

18. Wilson, W.H.; Mac Namee, R.W.; Durig, J. R. J. Raman Spect. 1981, 11, 252-255.

19. Santos, F.J.; Galceran. T. J. Choromatogr. A 2003, 1000, 125121.

20. Aebi, B.; Bernhard, W.Chimia 2002, 56, 48-52.

21. Li, H.; Sluggett, G. W. J. Pharm. Biomed. Anal. 2005, 39, 486494.

22. Okolo, B.; Park, C.; Keane, M.A. J. Coll. Inter. Sci. 2000, 226, 308-317. 